\title{
Produtividade e qualidade fisiológica de sementes de feijão caupi em função da adubação nitrogenada ${ }^{1}$
}

\author{
Yield and seed quality of cowpea as a function of nitrogen fertilization
}

\author{
Alek Sandro Dutra ${ }^{2 *}$, Francisco Thiago Coelho Bezerra ${ }^{3}$, Paulo Roberto Nascimento e Denise de Castro Lima ${ }^{3}$
}

\begin{abstract}
RESUMO - Objetivou-se com este trabalho avaliar níveis e formas de aplicação de nitrogênio sobre a produtividade e a qualidade fisiológica de sementes de feijão caupi. O trabalho foi desenvolvido no Campus do Pici da Universidade Federal do Ceará. As parcelas foram constituídas por seis linhas de $5 \mathrm{~m}$ espaçadas em $0,5 \mathrm{~m}$, sendo a área útil às quatro linhas centrais desprezando-se $0,5 \mathrm{~m}$ em ambas as extremidades. A densidade de semeadura foi de 12 sementes $\mathrm{m}^{-1}$. Nessa etapa obteve-se a produtividade de sementes. A qualidade fisiológica das sementes foi avaliada a partir dos testes: germinação, primeira contagem, emergência de plântulas, índice de velocidade de emergência e, massa seca da parte aérea. Os tratamentos consistiram na ausência de adubação nitrogenada e nas adubações com 15 e $30 \mathrm{~kg}^{-1} \mathrm{de}^{-1}$ nitrogênio em fundação e em cobertura. As médias foram comparadas pelo teste de Tukey a 5\% de probabilidade. As adubações nitrogenadas não influenciaram a produtividade das plantas, a germinação das sementes e as variáveis de vigor primeira contagem, percentual de emergência e massa seca da parte aérea. $O$ índice de velocidade de emergência foi afetado pela adubação nitrogenada, com os maiores valores obtidos das sementes oriundas das plantas não adubação e adubadas com nitrogênio na fundação, independente do nível. As adubações nitrogenadas, aqui empregadas, não interferem na produtividade das plantas e na qualidade fisiológica das sementes de feijão caupi cv. canapuzinho.
\end{abstract}

Palavras-chave: Vigna unguiculata. Produtividade. Germinação. Vigor.

\begin{abstract}
The objective of this study was to evaluate different levels and modes of nitrogen application on the yield and physiological quality of the black-eyed or cow-pea. The work was carried out on the Pici Campus of the Federal University of Ceará. The plots were made up of six rows of $5 \mathrm{~m}$, spaced $0.5 \mathrm{~m}$ apart, the available area consisting of the four central rows, disregarding $0.5 \mathrm{~m}$ at either end. Seeding density was $12 \mathrm{seeds}^{-1}$. At this stage, productivity from the seeds was obtained. The physiological quality of the seeds was evaluated by means of the following tests: germination, first count, emergence of seedlings, rate of emergence and shoot dry mass. The treatments consisted of the absence of nitrogen fertilization and of fertilization with 15 and $30 \mathrm{~kg} \mathrm{ha}^{-1}$ of nitrogen, both in the soil and on the surface. Averages were compared using the Tukey test at $5 \%$ probability. Nitrogen fertilization did not affect plant productivity, seed germination nor the variables of vigour: first count, percentage of emergence and shoot dry mass. Nitrogen fertilization however did affect the rate of emergence, with the highest values being obtained from the seeds derived from unfertilized plants, and from those fertilized with nitrogen in the soil, regardless of the depth. Nitrogen fertilization as used here does not interfere with plant yield or with the physiological quality of cow-pea seeds cv. canapuzinho.
\end{abstract}

Key words: Vigna unguiculata. Productivity. Germination. Vigour.

\footnotetext{
*Autor para correspondência

'Recebido para publicação em 25/09/2011; aprovado em 30/03/2012

Pesquisa realizada na Universidade Federal do Ceará

${ }^{2}$ Departamento de Fitotecnia do Centro de Ciências Agrárias, Universidade Federal do Ceará, Caixa Postal 12.168, Campus do Pici, Fortaleza-CE, Brasil, 60.356-001, alekdutra@ufc.br

${ }^{3}$ Programa de Pós-Graduação em Agronomia/Fitotecnia, Universidade Federal do Ceará, Caixa Postal 12.168, Campus do Pici, Fortaleza-CE, Brasil, 60.356-001, bezerra_ftc@yahoo.com.br, dennisedecastro@gmail.com

${ }^{4}$ Universidade Federal do Ceará, Caixa Postal 12.168, Campus do Pici, Fortaleza-CE, Brasil, 60.356-001
} 


\section{INTRODUÇÃO}

O feijão caupi (Vigna unguiculata (L.) Walp.) é uma das leguminosas mais consumidas no Norte e Nordeste do Brasil, representando importante fonte de proteína, energia, fibras e minerais, além de gerador de emprego e renda (ROCHA, 2009). Estimativas da CONAB (2011) apontam para a safra de 2010-2011 produção de 3.713 .400 toneladas de grãos, com produtividade de $956 \mathrm{~kg} \mathrm{ha}^{-1}$. Produtividade esta, superior à média do decênio 2000 a 2009 que foi de 797,3 $\mathrm{kg} \mathrm{ha}^{-1}$ (IBGE, 2010).

No Nordeste brasileiro registram-se os menores rendimentos do feijão, estimado para a safra 2010$2011 \mathrm{em} 482 \mathrm{~kg} \mathrm{ha}^{-1}$ (CONAB, 2011). A produtividade Nordestina e nem mesmo a Brasileira refletem o potencial produtivo do feijão. De acordo com Rosolem e Marubayashi (1994), os sistemas de produção, os efeitos climáticos, a sanidade da cultura e até problemas econômicos dos agricultores, são fatores que levam a baixas produtividades.

O manejo da fertilidade do solo também contribui para a baixa produtividade do feijão, particularmente pelo insuficiente suprimento de nitrogênio (HUNGRIA; BARRADAS; VALLSGROVE,1991; MARTINS et al., 2003) que é absorvido praticamente durante todo o ciclo da cultura (ROSOLEM; MARUBAYSHI, 1994). A nutrição adequada também proporciona a produção de sementes de melhor qualidade (KIKUTI et al., 2006).

O solo, a aplicação de adubos nitrogenados e fixação biológica de nitrogênio atmosférico são as principais fontes de nitrogênio para o feijão (HUNGRIA; VARGAS; ARAUJO, 1997). Dessa forma, a adubação nitrogenada e/ou a inoculação das sementes com rizóbio, em leguminosas, devem ser adotadas a fim de se elevar a produtividade. A adubação nitrogenada favorece tanto o aumento da produtividade (MELO; ZILLI, 2009; OLIVEIRA et al., 2003; XAVIER et al., 2008; ZILLI et al., 2006) como a produção de sementes de melhor qualidade fisiológica (FARINELLI et al., 2006; OLIVEIRA et al., 2001; TOLEDO et al., 2009).

A utilização de sementes de alta é um dos fatores de suma relevância para obtenção de elevadas produtivas das culturas, por isso, a produção e a comercialização desse tipo de sementes se concretiza como uma necessidade e uma realidade no setor agrícola. De acordo com FrançaNeto, Krzyzanowski e Henning (2010), a semente possui atributos de qualidades genética, física, fisiológica e sanitária, o que lhe confere a garantia de um elevado desempenho agronômico, que é a base fundamental do sucesso para uma lavoura tecnicamente bem instalada.

Os agricultores têm exigido, cada vez mais, sementes de alta qualidade, que possibilitem a emergência rápida e uniforme no campo (KIKUTI et al., 2002). A emergência de plantas no campo pode variar, mesmo para lotes de semente de alta germinação, em função do vigor das sementes (RAMOS et al., 2004), sendo os testes de vigor essenciais para a complementação das informações da qualidade do lote de sementes.

Diante do exposto, o presente trabalha objetivou avaliar o efeito da adubação nitrogenada sobre a produtividade e a qualidade fisiológica de sementes de feijão caupi cv. canapuzinho.

\section{MATERIAL E MÉTODOS}

O trabalho foi desenvolvido na área Experimental e no Laboratório de Análise de Sementes do Departamento de Fitotecnia do Campus do Pici ( $3^{\circ} 44^{\prime} \mathrm{S}, 38^{\circ} 33^{\prime} \mathrm{W}$ e $19,5 \mathrm{~m}$ de altitude) da Universidade Federal do Ceará, Fortaleza - CE. Segundo a classificação de Köppen o clima da região é do tipo Aw', ou seja, clima tropical de estações úmida e seca.

A semeadura do feijão caupi cultivar canapuzinho, foi realizada no dia 13 de agosto de 2010 e a colheita em 18 de outubro de 2010. Previamente à instalação da cultura, foram retiradas amostras do solo, na camada de $0-20 \mathrm{~cm}$ do perfil, para caracterização química, possuindo: 6,6 de $\mathrm{pH}$ em água; $5,58 \mathrm{~g} \mathrm{~kg}^{-1}$ de matéria orgânica; $0,32 \mathrm{~g} \mathrm{~kg}^{-1}$ de $\mathrm{N}$ total; $18 \mathrm{mg} \mathrm{kg}^{-1}$ de $\mathrm{P}$ assimilável; $0,32 \mathrm{dS} \mathrm{m}^{-1}$ de condutividade elétrica do extrato de saturação; $81 \%$ de saturação por bases (V); 1,6; 1,3; 0,09; 0,05; 0,66 e; 0,1 $\mathrm{cmol}_{\mathrm{c}} \mathrm{kg}^{-1} \mathrm{de} \mathrm{Ca}^{2+}$, $\mathrm{Mg}^{2+}, \mathrm{Na}^{+}, \mathrm{K}^{+}, \mathrm{H}^{+}+\mathrm{Al}^{3+}$ e $\mathrm{Al}^{3+}$, respectivamente.

O preparo da área para o cultivo consistiu em aração e gradagem. A semeadura foi realizada manualmente, no espaçamento entre as linhas de $0,5 \mathrm{~m}$ e densidade de 12 sementes $\mathrm{m}^{-1}$, sendo o replantio realizado após seis dias. As parcelas formam constituídas por seis linhas de $5 \mathrm{~m}$, sendo consideradas áreas úteis às quatro linhas centrais, desprezando-se 0,5 $\mathrm{m}$ em ambas as extremidades.

As adubações, fosfatada e potássica, foram realizadas em fundação com os fertilizantes: superfosfato simples e cloreto de potássio nas doses de $60 \mathrm{~kg} \mathrm{ha}^{-1}$ de $\mathrm{P}_{2} \mathrm{O}_{5}$ e $30 \mathrm{~kg} \mathrm{ha}^{-1}$ de $\mathrm{K}_{2} \mathrm{O}$, respectivamente. As adubações nitrogenadas foram realizadas com ureia em fundação e em cobertura, 26 dias após a semeadura. O manejo da adubação nitrogenada constituíram os tratamentos avaliados, sendo a ausência de adubação e as adubações com 15 e $30 \mathrm{~kg} \mathrm{ha}^{-1}$ de nitrogênio em fundação e em cobertura, totalizando cinco tratamentos com quatro repetições.

Os tratos culturais consistiram em capinas e na aplicação dos inseticidas Decis 50 e Thiodan, a fim de, 
combater o pulgão e o percevejo vermelho do feijoeiro. A colheita foi efetuada manualmente, em um ciclo de 66 dias. A partir dos dados de produção calculou-se a produtividade de sementes e, em seguida, amostras foram retiradas com o objetivo de avaliar a qualidade fisiológica das mesmas a partir dos seguintes testes: Teor de água: determinado utilizando-se quatro amostras de 25 sementes para cada tratamento, em estufa a $105 \pm 3{ }^{\circ} \mathrm{C}$, durante 24 horas, conforme as Regras para Análise de Sementes (BRASIL, 2009). Germinação: conduzido com quatro amostras de 50 sementes por tratamentos, em papel germiteste umedecido com água na proporção de 2,5 vezes a massa do substrato. Para cada repetição foram utilizadas três folhas e os rolos de papel foram acondicionados em sacos plásticos e mantidos em germinador do tipo B.O.D. a temperatura de $25{ }^{\circ} \mathrm{C}$, sendo a contagem das sementes germinadas realizadas aos oito dias após a semeadura (BRASIL, 2009). Primeira contagem de germinação: realizado concomitante ao teste padrão de germinação, sendo a contagem realizada aos cinco dias após a instalação. Emergência de plântulas em canteiro: realizada com quatro amostras de 25 sementes por tratamento em canteiro contendo como substrato terra e areia em proporções iguais. As sementes foram semeadas em sulco a $2 \mathrm{~cm}$ de profundidade e a contagem das plântulas emergidas foi efetuada aos 14 dias após a semeadura com expressão dos resultados em porcentagem. Índice de velocidade de emergência: realizado concomitante ao teste de emergência de plântulas em canteiro, sendo a contagem realizada diariamente desde o primeiro dia após a semeadura até o $14^{\circ}$ dia. A partir dos valores diários de plântulas emergidas foi-se calculado o índice de velocidade de emergência conforme Maguire (1962). Massa seca da parte área: obtida pela determinação da massa da parte aérea das plântulas provenientes do teste de emergência de plântulas, colhidas aos 14 dias após a semeadura e secadas em estufa com circulação de ar a $65^{\circ} \mathrm{C}$ até atingir peso constante, sendo os valores expressos em g plântula ${ }^{-1}$.
O trabalho de campo foi conduzido em delineamento experimental de blocos casualizados e os de laboratório em delineamento inteiramente casualizado. Os dados foram submetidos à análise de variância e as médias foram comparadas pelo teste de Tukey a $5 \%$ de probabilidade de erro.

\section{RESULTADOS E DISCUSSÃO}

Na Tabela 1 pode-se observar o resumo da análise de variância e na Tabela 2 os valores médios, médias e diferenças mínimas significativas referentes à produtividade das plantas, ao teste padrão de germinação e aos testes de vigor em sementes de feijão caupi cultivadas sem adubação nitrogenada e adubadas com 15 e $30 \mathrm{~kg} \mathrm{ha}^{-1}$ de nitrogênio em fundação e em cobertura. Observamse também os valores médios da umidade dos lotes de sementes determinadas previamente a estes testes.

As adubações nitrogenadas não afetaram a produtividade de sementes de feijão caupi (Tabela 1) obtendo-se, em média, $1.215,5 \mathrm{~kg} \mathrm{ha}^{-1}$ (Tabela 2). Já Oliveira et al. (2003), estimam o máximo rendimento de vargem verde e de grãos, verde e seco, do cv. IPA-206 ao se aplicar de 55,5 a 60,9 $\mathrm{kg} \mathrm{ha}^{-1}$ de nitrogênio via solo e de 59,5 a $64,3 \mathrm{~kg} \mathrm{ha}^{-1}$ de nitrogênio via foliar. Enquanto Xavier et al. (2008), estimam a máximo produtividade de grãos do cv. BRS-Guariba ao se aplicar os níveis de 50,2 e $96,6 \mathrm{~kg} \mathrm{ha}^{-1}$ de nitrogênio quando as sementes não foram e foram, respectivamente, inoculadas com Bradyrhizobium sp, estirpe BR2001.

A manutenção de níveis adequados de nitrogênio, no solo e na planta, pode proporciona desempenho satisfatório das culturas. Dessa forma, a adubação nitrogenada e/ou a inoculação das sementes com rizóbio, em leguminosas, devem ser adotadas a fim de se elevar a

Tabela 1 - Resumo da análise de variância referente à produtividade, ao teste de germinação e aos testes de vigor (PC - primeira contagem de germinação; IVE - índice de velocidade de plântulas; EP - emergência de plântulas em canteiro e; MSPA - massa seca de plântulas) em sementes de feijão caupi cv. canapuzinho cultivadas sem adubação, e com adubação de 15 e $30 \mathrm{~kg} \mathrm{ha}^{-1}$ de nitrogênio em fundação e em cobertura

\begin{tabular}{lcccccc}
\hline & \multicolumn{5}{c}{ Quadrado Médio } \\
\cline { 2 - 7 } Fonte de variação & Produtividade & Germinação & \multicolumn{4}{c}{ Vigor } \\
\cline { 3 - 7 } & 19519,00 & - & PC & IVE & EP & MSPA \\
\hline Bloco & $83544,63^{\text {ns }}$ & $13,50^{\text {ns }}$ & $46,71^{\text {ns }}$ & $0,4761^{* *}$ & $10,00^{\text {ns }}$ & $0,000068^{\text {ns }}$ \\
Tratamento & 98012,29 & 5,53 & 18,53 & 0,0449 & 4,80 & 0,000268 \\
Resíduo & 25,76 & 2,61 & 4,46 & 2,69 & 2,24 & 8,6 \\
CV $(\%)$ & &
\end{tabular}

ns e **: não significativo e significativo a $1 \%$, respectivamente, pelo teste $\mathrm{F}$ de Snedecor 
Tabela 2 - Valores médios, médias e diferenças mínimas significativas (DMS) da produtividade, do teor de água, do teste de germinação e dos testes de vigor (PC - primeira contagem de germinação; IVE - índice de velocidade de plântulas; EP - emergência de plântulas em canteiro e; MSPA - massa seca de plântulas) em sementes de feijão caupi cv. canapuzinho cultivadas sem adubação, e com adubação de 15 e $30 \mathrm{~kg} \mathrm{ha}^{-1}$ de nitrogênio em fundação e em cobertura

\begin{tabular}{|c|c|c|c|c|c|c|c|}
\hline \multirow{2}{*}{ Tratamentos } & \multirow{2}{*}{ Produtividade $\left(\mathrm{kg} \mathrm{ha}^{-1}\right)$} & \multirow{2}{*}{ Umidade $(\%)$} & \multirow{2}{*}{ Germinação (\%) } & \multicolumn{4}{|c|}{ Vigor } \\
\hline & & & & $\mathrm{PC}(\%)$ & IVE & $\mathrm{EP}(\%)$ & $\operatorname{MSPA}(\mathrm{g})$ \\
\hline \multicolumn{8}{|c|}{ 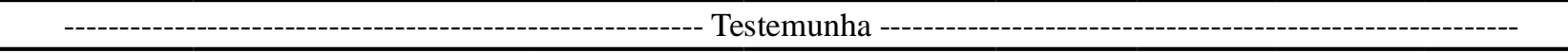 } \\
\hline $0,0 \mathrm{~kg} \mathrm{ha}^{-1}$ & $1.079,25 \mathrm{a}$ & 11,9 & $97,5 \mathrm{a}$ & $97,5 \mathrm{a}$ & $8,27 \mathrm{a}$ & $100,0 \mathrm{a}$ & $0,188 \mathrm{a}$ \\
\hline \multicolumn{8}{|c|}{  } \\
\hline $15 \mathrm{~kg} \mathrm{ha}^{-1}$ & $1.441,75 \mathrm{a}$ & 11,8 & $99,5 \mathrm{a}$ & $99,5 \mathrm{a}$ & $8,09 \mathrm{ab}$ & $99,0 \mathrm{a}$ & $0,198 \mathrm{a}$ \\
\hline $30 \mathrm{~kg} \mathrm{ha}^{-1}$ & $1.168,50 \mathrm{a}$ & 12,8 & $99,0 \mathrm{a}$ & $99,0 \mathrm{a}$ & $7,90 \mathrm{ab}$ & $96,0 \mathrm{a}$ & $0,188 \mathrm{a}$ \\
\hline \multicolumn{8}{|c|}{ - } \\
\hline $15 \mathrm{~kg} \mathrm{ha}^{-1}$ & $1.121,00 \mathrm{a}$ & 11,7 & $99,0 \mathrm{a}$ & $96,0 \mathrm{a}$ & $7,36 \mathrm{c}$ & $97,0 \mathrm{a}$ & $0,190^{\mathrm{a}}$ \\
\hline $30 \mathrm{~kg} \mathrm{ha}^{-1}$ & $1.267,00 \mathrm{a}$ & 11,8 & $95,0 \mathrm{a}$ & $91,0 \mathrm{a}$ & $7,79 b c$ & $98,0 \mathrm{a}$ & $0,190^{\mathrm{a}}$ \\
\hline Média & $1.215,50$ & - & 98,0 & 96,6 & 7,88 & 98,0 & 0,191 \\
\hline DMS & 705,85 & - & 5,6 & 9,4 & 0,46 & 4,79 & 0,036 \\
\hline
\end{tabular}

Médias seguidas por mesma letra, na coluna, não diferem entre si pelo teste de Tukey a 5\%

produtividade. No cv. BRS-Manzagão a adubação com 50 ou $80 \mathrm{~kg} \mathrm{ha}^{-1}$ de nitrogênio ou a inocular com as estirpes de rizóbio BR3262 ou INPA03-11B elevam a produção (ZILLI et al., 2006) e no cv. BRS-Guariba, a combinação da inoculação das sementes e a adubação de até $20 \mathrm{~kg} \mathrm{ha}^{-1}$ de nitrogênio também elevaram a produtividade (XAVIER et al., 2008). Mello e Zilli (2009), também obtiveram elevação significativa da produtividade de cultivares de feijão caupi com o uso da adubação nitrogenada ou da inoculação das sementes.

Mas, nem sempre a adubação nitrogenada e/ou a inoculação favorecem o aumento da produtividade do feijão caupi (GUALTER et al., 2008; GUEDES et al., 2010; SILVA et al., 2011) pois, diversos fatores interferem e interagem no desenvolvimento e produção das culturas. Teixeira et al. (2010), estudando cultivares de feijão caupi, obtiveram as maiores produtividades com BRSGuariba e BRS-Gurgéia, sendo, respectivamente, de 2.221 e $2.196 \mathrm{~kg} \mathrm{ha}^{-1}$ de grãos e as menores produtividades com BRS-Milênio e CE-315, sendo, respectivamente, de 769 e $675 \mathrm{~kg} \mathrm{ha}^{-1}$ de grãos. Dessa forma, a escolha do cultivar, do manejo da adubação, da inoculação das sementes com rizóbio ou a combinadas destes fatores, é de suma importância para um bom rendimento da cultura.

A qualidade fisiológica das sementes de feijão caupi, considerando-se o teste de germinação, não foi afetada pelo manejo da adubação nitrogenada (Tabela 1) que variou de 95 a 99\%, com média de $98 \%$ (Tabela 2). Já Oliveira et al. (2001), estimam um acréscimo na germinação de sementes do cv. IPA-206 de 0,192\% para cada $1 \mathrm{~kg} \mathrm{ha}^{-1} \mathrm{de}$ nitrogênio aplicado no solo. Com Phaseolus vulgaris L. cv. Pérola, Farinelli et al. (2006), obtiveram aumento de 0,1\% no percentual de germinação das sementes para cada $1 \mathrm{~kg}$ de nitrogênio aplicado. Com este cv. Pérola, Toledo et al. (2009), também obtiveram valores crescentes de germinação das sementes das plantas cultivadas com maiores níveis de adubação nitrogenada no estádio de desenvolvimento $\mathrm{R}_{7}$, que pôde ser potencializada ao se associar com uma aplicação de $90 \mathrm{~kg} \mathrm{ha}^{-1}$ de nitrogênio no estádio $\mathrm{V}_{4}$.

Estudando a adubação nitrogenada em feijão de corda cv. IAC-Carioca, Crusciol et al. (2003), não encontraram diferenças significativas na forma (semeadura e cobertura) e nas doses $\left(0 ; 12,5\right.$ e $\left.25 \mathrm{~kg} \mathrm{ha}^{-1}\right)$ aplicadas sob a germinação das sementes. Isso se deve, pois, diversos fatores interagem e interferem no potencial germinativo das sementes como, por exemplos, a cultivar utilizada e as técnicas utilizadas durante e após o cultivo.

$\mathrm{Na}$ região do cerrado, Teixeira et al. (2010), encontraram os maiores percentuais de germinação com os cultivares CE315, BRS Rouxinol, Patativa, BRS Gurgéia e BRS Marataoã, sendo de 95, 92, 89, 88 e $88 \%$, respectivamente, e iguais entre si e superiores o cv. Tracuateua, com $67 \%$ de germinação. O local de cultivo também interfere sobre as características agronômicas e na qualidade das sementes produzidas. Dutra et al. (2007), encontraram diferentes respostas ao se estudar cultivares de feijão caupi em quatro localidades do Estado do Ceará. Dessa forma, se faz necessário realizar estudos referentes ao manejo das adubações para as diferentes cultivares em diversos sistemas e ambientes de cultivo. 
Para as variáveis de vigor, primeira contagem de germinação e emergência e massa seca da parte aérea de plântulas o manejo da adubação nitrogenada não as afetaram (Tabela 1), apresentando, respectivamente, as médias: 96 e 98\% e 0,191g (Tabela 2). Já o índice de velocidade de emergência (Tabela 1) foi afetado pela adubação nitrogenada. Com o cv. IPA-206, Oliveira et al. (2001), obtiveram valores crescentes na primeira contagem da germinação de sementes cultivadas em função da adubação nitrogenada. Toledo et al. (2009) com o cultivar Pérola e Gomes Jr. e Sá (2010), com o cultivar IPR Jurití, também observaram que o aumento dos níveis de nitrogênio aplicados em cobertura proporcionou acréscimo na primeira contagem de germinação das sementes.

Porém, a forma e o nível de adubação nitrogenada também podem influenciar negativamente sobre a primeira contagem. Smiderle e Schwengber (2008) obtiveram, com o cv. BRS-Manzagão, redução da primeira contagem da germinação das sementes cultivadas com os maiores níveis de adubação nitrogenada. Para o cultivar IAC-Carioca, a adubação nitrogenada de cobertura não afetou a primeira contagem de germinação, mas, quando o nitrogênio foi aplicado na adubação de fundação no nível de $25 \mathrm{~kg} \mathrm{ha}^{-1}$, a primeira contagem foi reduzida, quando comparadas das sementes oriundas dos níveis de 0,0 e $12,5 \mathrm{~kg} \mathrm{ha}^{-1}$ (CRUSCIOL et al., 2003).

Os maiores valores do índice de velocidade de emergência foram obtidos das sementes oriundas das plantas cultivadas sem adubação nitrogenada e adubadas com nitrogênio em fundação, com 15 e $30 \mathrm{~kg} \mathrm{ha}^{-1}$ de nitrogênio, sendo iguais entre si e superiores daquelas adubadas com $15 \mathrm{~kg} \mathrm{ha}^{-1}$ de nitrogênio em cobertura (Tabela 2). Crusciol et al. (2003), obtiveram, quando adubaram o feijão de corda cv. IAC-Carioca, os menores valores de velocidade de emergência com o maior nível de nitrogênio ( $\left.25 \mathrm{~kg} \mathrm{ha}^{-1}\right)$, sendo estatisticamente inferior daquelas sementes oriundas das plantas não adubadas. Já quando a adubação foi em cobertura, este índice não foi afetado. Gomes Jr. e Sá (2010) obtiveram com o cultivar IPR Juriti uma elevação do índice de velocidade de emergência das sementes oriundas das plantas adubadas até o nível de $80 \mathrm{~kg} \mathrm{ha}^{-1}$ de nitrogênio. $\mathrm{O}$ índice de velocidade de emergência também é facilmente influenciado pelo cultivar utilizada e o local de cultivo (DUTRA et al., 2007).

Já o vigor das sementes avaliado pelo percentual de emergência de plântulas é mais influenciado pelo cultivar utilizada (TEIXEIRA et al., 2010) do que pelo local de cultivo (DUTRA et al., 2007). As respostas relacionadas ao manejo da adubação nitrogenada devem ser avaliadas para os diversos cultivares. Com o cultivar Pérola, Gomes Jr. e Sá (2010), obtiveram repostas díspares com os dados de emergência de plântulas. Estes autores obtiveram redução na emergência de plântulas quando oriundas de plantas adubadas, na fase $\mathrm{V}_{4-3}$ (terceiro folíolo da haste principal expandido), até o nível de $76 \mathrm{~kg} \mathrm{ha}^{-1}$ de nitrogênio. Já ao se adubar na fase $\mathrm{V}_{4-6}$ (sexto folíolo da haste principal expandido), houve acréscimo no valor do teste até a dose de $101 \mathrm{~kg} \mathrm{ha}^{-1}$ de nitrogênio.

$\mathrm{Na}$ avaliação da biomassa seca de plântulas oriundas de 25 genótipos de feijão de corda cultivados sem e com adubação, Kikuti et al. (2006), observaram que a adubação não afetou a biomassa seca das plântulas encontrando diferenças significativas apenas entre os genótipos. Já Toledo et al. (2009) estimam, para o cultivar Pérola, um acréscimo na massa seca de plântulas quando as sementes foram oriundas de plântulas adubadas até $\mathrm{o}$ nível de $57 \mathrm{~kg} \mathrm{ha}^{-1}$ de nitrogênio na fase $R_{7}$.

\section{CONCLUSÕES}

A adubação nitrogenada em feijão caupi cv. canapuzinho nos níveis de 15 e $30 \mathrm{~kg} \mathrm{ha}^{-1}$, na fundação ou na cobertura, não interferem na produtividade das plantas e na qualidade fisiológica das sementes.

\section{REFERENCIAS}

BRASIL. Ministério da Agricultura, Pecuária e Abastecimento. Regras para Análise de Sementes. Ministério da Agricultura, Pecuária e Abastecimento. Secretaria de Defesa Agropecuária. Brasília: MAPA/ACS, 2009. 395p.

CONAB - Companhia Nacional de Abastecimento. Acompanhamento da safra Brasileira: grãos, sexto levantamento, março de 2011. Conab, 2011.

CRUSCIOL, C. A. C. et al. Efeito do nitrogênio sobre a qualidade fisiológica, produtividade e características de sementes de feijão. Revista Brasileira de Sementes, v. 25, n. 01, p. 108-115, 2003.

DUTRA, A. S. et al. Qualidade fisiológica de sementes de feião caupi em quatro regiões do Estado do Ceará. Revista Brasileira de Sementes, v. 29, n. 02, p. 111-116, 2007.

FARINELLI, R. et al. Produtividade e qualidade fisiológica de sementes de feijão em função de sistema de manejo de solo e a adubação nitrogenada. Revista Brasileira de Sementes, v. 28, n. 02, p. 102-109, 2006.

FRANÇA-NETO, J. B.; KRZYZANOWSKI, F. C.; HENNING, A. A. A importância do uso de semente de soja de alta qualidade. Informativo ABRATES, v. 20, n. 1,2, p. 37-38, 2010.

GOMES JR., F. G.; SÁ, M. E. Proteína e qualidade de sementes de feijão (Phaseolus vulgaris L.) em função da adubação nitrogenada em plantio direto. Revista Brasileira de Sementes, v. 32, n. 01, p. 34-44, 2010.

GUALTER, R. M. R. et al. Inoculação e adubação mineral em feijão-cupi: efeitos na nodulação, crescimento e produtividade. Scientia Agraria, v. 9, n. 04, p. 469-474, 2008. 
GUEDES, G. N. et al. Eficiência agronômica de inoculantes de feijão-caupi no município de Pombal - PB. Revista Verde, v. 05 , n. 04 , p. $82-89,2010$.

HUNGRIA, M.; BARRADAS, C. A.; VALLSGROVE, R. M. Nitrogen fixation, assimilation and transport during the initial growth stage of Phaseolus vulgaris L. Journal of Experimental Botany, v. 42, n. 07, p. 839-844, 1991.

HUNGRIA, M.; VARGAS, M. A. T.; ARAUJO, R. S. Fixação biológica de nitrogênio em feijoeiro. In: VARGAS, M.A.T.; HUNGRIA, M. Biologia dos solos dos cerrados. Planaltina, Embrapa-CPAC, 1997. p.189-294.

IBGE - Instituto Brasileiro de Geografia e Estatística. Levantamento sistemático da produção agrícola: pesquisa mensal de previsão e acompanhamento das safras agrícolas no ano civil. IBGE, v. 23, n. 09, p. 1-80, 2010.

KIKUTI, H. et al. Qualidade de sementes de genótipos de feijão em função da adubação. Revista Ciência Agronômica, v. 37, n. 01 , p. 37-43, 2006.

KIKUTI, A. L. P. et al. Armazenamento e qualidade fisiológica de sementes de algodão submetidas ao condicionamento osmótico. Revista Ciência e Agrotecnologia, Lavras, v. 26, n. 02, p. 439-443, 2002.

MAGUIRE, J. D. Speed of germination-aid selection and evaluation for seedling emergence and vigor. Crop Science, Madison, v. 02, p. 176-177, 1962.

MARTINS, L. M. et al. Contribution of biological nitrogen fixation to cowpea: a strategy for improving grain yield in the semi-arid region of Brazil. Biology and Fertility of Soils, v. 38, n. 06, p. 333-339, 2003.

MELO, S. R.; ZILLI, J. E. Fixação biológica em cultivares de feijão-caupi recomendadas para o Estado de Roraima. Pesquisa Agropecuária Brasileira, v. 44, n. 9, p. 1177-1183, 2009.

OLIVEIRA, A. P. et al. Produção e qualidade de sementes de feijão-caupi (Vigna unguiculata (L.) Walp.), em função de doses e formas de aplicação de nitrogênio. Revista Brasileira de Sementes, v. 23, n. 02, p. 215-221, 2001.

OLIVEIRA, A. P. et al. Rendimento de feijão-caupi em função de doses e formas de aplicação de nitrogênio. Horticultura Brasileira, v. 21, n. 1, p. 77-80, 2003.

RAMOS, N. P. et al. Envelhecimento acelerado em sementes de rúcula (Eruca sativa L.). Revista Brasileira de Sementes, Pelotas, v. 26, n. 01, p. 98-103, 2004.

ROCHA, M.M. O feijão-caupi para consumo na forma de feijão fresco. 2009. Disponível em: < www.agrosoft.org.br/ agropag/212374.htm>. Acesso em: 13 jan. 2011.

ROSOLEM, C. A; MARUBAYASHI, O. M. Seja o doutor do seu feijão. Potafos, encarte do informações agronômicas $n^{\circ} 68$ (arquivo do agrônomo $\mathrm{n}^{\circ}$ 7), 1994.

SILVA, R. T. L. et al. Inoculação e adubação nitrogenada na cultura do feijão-caupi em Latossolos da Amazônia oriental. Revista Caatinga, v. 24, n. 04, p. 152-156, 2011.

SMIDERLE, O. J.; SCHWENGBER, D. R. Rendimento e qualidade de sementes de feijão-caupi em função de doses de nitrogênio. Agro@mbiente On-line, v. 2, n. 01, p. 18-21, 2008.

TEIXEIRA, I. R. et al. Desempenho agronômico e qualidade de sementes de cultivares de feijão-caupi na região do cerrado. Revista Ciência Agronômica, v. 41, n. 02, p. 300-307, 2010.

TOLEDO, M. Z. et al. Qualidade fisiológica e armazenamento de sementes de feijão em função da aplicação tardia de nitrogênio em cobertura. Pesquisa Agropecuária Tropical, v. 39, n. 02 , p. 124-133, 2009

XAVIER, T. F. et al. Inoculação e adubação nitrogenada sobre a nodulação e a produtividade de grãos de feijão-caupi. Ciência Rural, v. 38, n. 07, p. 2037-2041, 2008.

ZILLI, J. E. et al. Avaliação de estirpes de rizóbio para a cultura do feijão-caupi em Roraima. Boa Vista, Embrapa Roraima, 2006. 8p. (Embrapa Roraima. Comunicado Técnico, 01). 